\title{
Phenol Adsorption from Crude and Active Coals
}

\author{
Boucheta Abbes $^{1 *}$, Bared Razika ${ }^{1}$, Chaib Messaoud ${ }^{2}$, Soufi Kacimi ${ }^{1}$, Kadouri Naima $^{3}$ \\ ${ }^{1}$ Laboratory of materials and catalysis, Faculty of Sciences, Djilali Liabes University, \\ Sidi Bel-Abbès, Algeria. \\ ${ }^{2}$ Laboratory of Environmental Chemistry Faculty of Science, University Ibn Khaldoun, \\ Tiaret, Algeria. \\ ${ }^{3}$ Faculty of Sciences, University of Bechar, Bechar, Algeria. \\ E-mail:abbes.hissi@yahoo.fr \\ Received June 11, 2010; revised June 21, 2010; accepted July 3, 2010
}

\begin{abstract}
The aim of the present work is the removal of phenol by adsorption on a raw and activated crude or hard coal (C) with $\mathrm{NaOH}, \mathrm{ZnCl}_{2}$ and $\mathrm{H}_{3} \mathrm{PO}_{4}$ in the region of Bechar (south-western Algeria). The development of adsorbents from precursors is inexpensive, requiring innovative techniques using concepts developed relevant to the physical handling, processing physical and chemical activation of coal into an activated coal, with the ability of fixing aromatic organic pollutants, namely phenol. The maximum surface area obtained from the activation with $\mathrm{ZnCl}_{2}, \mathrm{H}_{3} \mathrm{PO}_{4}$ and $\mathrm{NaOH}$ were 1000,850 and $3000 \mathrm{~m}^{2} / \mathrm{g}$, respectively. The results clearly showed that hard coal activation greatly improved phenol fixing. The rate of phenol adsorption by activated hard coal is much higher than those obtained from raw coal through its holding capacity. Activated carbon porosity with $\mathrm{NaOH}$ is much higher than those obtained from coal activated by $\mathrm{ZnCl}_{2}$ and $\mathrm{H}_{3} \mathrm{PO}_{4}$. Activated coal can be an effective means of confinement in industrial disposal sites, avoiding migration of organic pollutants contained in these wastes to groundwater via the adsorption phenomenon. The development of such effective barriers, based on local resources can help solve the problem of water contamination.
\end{abstract}

Keywords: Activated Coal, Crude Coal, Chemical Activation, Adsorption

\section{Introduction}

Phenol is a highly toxic and carcinogenic compound and its adsorption is very important to meet the environmental regulations.

The content of phenolic compounds in industrial waste water (about $200-2000 \mathrm{mg} / \mathrm{L}$ ) is generally higher than the standard norms (mostly less than $0.5 \mathrm{mg} / \mathrm{L}$ ) prepared for their release into the environment water [1].

Active Coal adsorption is one of the most effective technologies for removing organic substances and toxic dyes. Nevertheless, basic study of adsorption kinetics must be considered in advance. For an efficient adsorption process, the kinetic study allows the rapid removal of pollutants from the solution while the adsorption equilibrium is the ultimate capacity of adsorption [2].

In principle, the process for the preparation of activated carbons can be divided into two tests using physical and chemical methods. The physical method consists in the carbonization of precursors followed by gasifica- tion of coal resulting in steam or carbon dioxide [3-5].

The formation of a porous structure is obtained by the removal of a large amount of internal carbon mass.

The coal at high porosity can be obtained only at high levels of burned coal. The chemical method was carried out by carbonization of the raw material impregnated with a chemical reagent (eg, $\mathrm{ZnCl}_{2}, \mathrm{H}_{3} \mathrm{PO}_{4}$ and $\mathrm{NaOH}$ ). Due to the properties of dehydrogenation, reagents favor the formation of chemical crosslink, leading to the formation of a rigid matrix, less prone to volatile loss and volume contraction during carbonization [6-8].

Adsorption is one of the most effective methods of advanced wastewater treatment that industries employ to reduce the hazardous waste organic and inorganic effluents. It is also used to remove toxic organic compounds and inorganic-contaminated groundwater [9-10].

In this work a sample coal was chosen as a precursor of activated carbons, in addition to various activating agents, including $\mathrm{ZnCl}_{2}, \mathrm{H}_{3} \mathrm{PO}_{4}$ and $\mathrm{NaOH}$ were used in the preparation. Changes in behavior during the carbonization of the samples treated with these reagents were 
rarely studied and have, to our knowledge, never been compared in the literature. In the above framework, this paper describes the influence of different chemical reagents on weight loss behaviors during carbonization, and the development of surface characteristics of carbons prepared with carbonization temperature.

\section{Materials and Methods}

An Algerian Coal from the region of Bechar was used as the starting material. The characteristics of the adsorbent used are shown in Table 1. Unless otherwise specified, the particle sizes of the coal used for carbon preparation were within a range of $0.2 \mathrm{~mm}$.

\subsection{Pyrolysis}

About $45 \mathrm{~g}$ of Coal $(0.2 \mathrm{~mm})$ was heated to $1000^{\circ} \mathrm{C}$ in an atmosphere of the gases evolved during the pyrolysis process. Then, a quartz tube (i.d. $30 \mathrm{~mm}$ ) carrying the sample was inserted into a horizontal tabular furnace between 40 and $450 \mathrm{~mm}$ long. After that, the quartz tube was connected to a tar condenser. At the beginning of each experiment, air was removed from the system by purging with $\mathrm{N}_{2}$. The heating rate was $5^{\circ} \mathrm{C}$ min and the soaking time $30 \mathrm{~min}$. The yields of Coke, tar and gas were determined, but the gases from pyrolysis were not analyzed.

\subsection{Chemical Activation}

As stated in the preceding section, chemical activation of the Coal was performed using $\mathrm{ZnCl}_{2}, \mathrm{H}_{3} \mathrm{PO}_{4}$ and $\mathrm{NaOH}$ as reagents. The activation process was initiated in a 250 $\mathrm{ml}$ glass-stoppered flask by mixing $1 \mathrm{~g}$ of the as-received coal with a solution consisting of $50 \mathrm{~g}$ of water and 4.25 $\mathrm{g}$ of a chemical reagent. Then the flask was immersed in

Table 1. Characteristics of coals.

\begin{tabular}{lc}
\hline & Ultimate wt.\%, dry ash-free basis \\
\hline Hydrogen & $4.2-4.7$ \\
Nitrogen & $1.6-1.9$ \\
Sulfur & $1.2-4.2$ \\
Oxygen & $8.5-16.7$ \\
Inorganic Carbon & 0.2 \\
\hline & Proximate wt.\%, as-received \\
\hline Ash & $5-19$ \\
Total sulfur & $0.97-5.33$ \\
Humidity & $0.2-0.8$ \\
Volatile matter & $12.0-24.51$ \\
Fixed carbon & $46.3-56.3$ \\
Organic Carbon & $75.8-81.2$ \\
\hline
\end{tabular}

a constant-temperature shaker bath, with a shaker velocity of $100 \mathrm{rpm}$. The mixing was performed at $85^{\circ} \mathrm{C}$ and lasted for $3 \mathrm{~h}$. After mixing, the Coal slurry was subjected to vacuum drying at $110^{\circ} \mathrm{C}$ for $24 \mathrm{~h}$. The resulting chemical loaded samples were then carbonized in a horizontal cylindrical furnace $\left(60 \mathrm{~mm}\right.$ i.d) in $\mathrm{N}_{2}$ atmosphere, with a flow rate of $100 \mathrm{ml} / \mathrm{min}$. Carbonization was carried out by heating the samples at $30^{\circ} \mathrm{C} / \mathrm{min}$ from room temperature to carbonization temperatures in a range of $400-900^{\circ} \mathrm{C}$, followed by holding the samples at the carbonization temperature for $1 \mathrm{~h}$ before cooling under $\mathrm{N}_{2}$.

After cooling, the carbonized products that were treated with $\mathrm{ZnCl}_{2}$ or $\mathrm{NaOH}$ were then subjected to washing by stirring with $250 \mathrm{ml}$ of $0.5 \mathrm{~N} \mathrm{HCl}$ solutions at $85^{\circ} \mathrm{C}$ for $30 \mathrm{~min}$, followed by filtration of the mixture. The acid-washed samples were then leached by mixing with $250 \mathrm{ml}$ of distilled water at $85^{\circ} \mathrm{C}$ for several times until the $\mathrm{pH}$ value of the water-carbon mixture was above 6 . The leached products were then dried by vacuum at $110^{\circ} \mathrm{C}$ for $24 \mathrm{~h}$ to obtain the activated carbon products. As for the samples treated with $\mathrm{H}_{3} \mathrm{PO}_{4}$, an $\mathrm{NaOH}$ solution was used instead of the $\mathrm{HCl}$ solution in the washing process and the samples were leached by distilled water to reach a $\mathrm{pH}$ value less than 8 .

In order to better understand the carbonization process, a thermo gravimetric analyzer (TGA, Perkin-Elmer TGA 7) was employed to monitor the volatile evolution behavior by heating the chemical-loaded samples from room temperature to $900^{\circ} \mathrm{C}$ at $30^{\circ} \mathrm{C} / \mathrm{min}$. A sample of 30-50 mg was used for each TGA analysis.

Specific surface areas and pore volumes of the carbon products were determined by gas adsorption. An automated adsorption apparatus (Micromeritics, ASAP) was employed for these measurements.

Next, adsorption of $\mathrm{N}_{2}$, as probe species, was performed at $196^{\circ} \mathrm{C}$. Nitrogen surface areas and micropore volumes of the samples were determined from the BET and Dubinin-Radushkevich (D-R) Equations, respectively. The amount of $\mathrm{N}_{2}$ adsorbed at pressures corresponds to the total amount adsorbed at both microspores and mesopores; thereby subtracting of the micropore volume from the (D-R) Equation. The total amount of $\mathrm{N}_{2}$ (determined at $P / P_{0}=0.98$ in this case) will provide the volume of the mesopore [11].

\subsection{Kinetic studies}

Experiments were conducted by contacting known amounts of different adsorbents with $200 \mathrm{ml}$ of synthetic wastewater containing $70 \mathrm{mg} / \mathrm{l}$ of aqueous phenol solution.

The solution containing the adsorbents was left for $72 \mathrm{~h}$. After the equilibrium time, the treated solution was cen- 
trifuged and the supernatant solution was analyzed for intial concentration of phenol at $\lambda_{\max }=270 \mathrm{~nm}$ using $\mathrm{UV}$ spectrophotometry.

\subsection{Modeling the adsorption isotherm}

Modeling of the equilibrium data was done using Freundlich and Langmuir isotherms [12].

Langmuir Equation: The Langmuir Equation is the most widely used two-parameter equation, commonly expressed

$$
\begin{aligned}
\frac{C_{e q}}{q} & =\frac{1}{k_{l} q_{m}}+\frac{C_{e q}}{q_{m}} \\
\frac{1}{x / m} & =\frac{1}{q_{m}}+\frac{1}{q_{m} k_{l}} \cdot \frac{1}{C_{e q}}
\end{aligned}
$$

where:

$C_{e q}=$ equilibrium concentration of adsorbate in solution after adsorption; $x / m=$ amount adsorbed per adsorbent unit weight; and $k_{l}$ and $q_{m}$ are the Langmuir constants.

From a plot of $C_{e q} /(x / m)$ versus $C_{e q}, k_{l}(\mathrm{mg} / \mathrm{g})$ and $q_{m}$ $(\mathrm{L} / \mathrm{mg})$ can be determined from the slope and intercept, respectively. At equilibrium conditions, the adsorbed amount $x / m$ can also be predicted using the Freundlich Equation

$$
\frac{x}{m}=k_{F} \cdot\left(C_{e q}\right)^{1 / n}
$$

where the parameters $k$ and $n$ can be obtained using the linear form

$$
\log \frac{x}{m}=\log K_{F}+\frac{1}{n} \log C_{e q}
$$

where $k_{f}$ is an indication of the adsorbent capacity and $1 / n$ is a measure of the surface heterogeneity, ranging between 0 and 1, becoming more heterogeneous as its value gets closer to zero. Using

Equation (3) from the plot of $\log x / m$ versus $\log C_{e q}$, the parameters $n$ and $k$ were obtained from the slope and intercept, respectively.

Since the analysis of the isotherm is important in order to develop an Equation that accurately represents the results and which could be used for design purposes, two have been applied in this study, the Langmuir (1), Freundlich (2) out of the several isotherm Equations.

Adsorption model constants, the values which express the surface properties and affinity of the adsorbent, can be used for our Coal sample. The parameters in the models were estimated by nonlinear regression and by fitting transformed data to the linearized forms of the models.

\section{Results and Discussion}

Coal activated by $\mathrm{H}_{3} \mathrm{PO}_{4}, \mathrm{ZnCL}_{2}$, and $\mathrm{NaOH}$ was used for the removal of phenol.

Using Equation (2), from the plot of $\log (x / m)$ versus $\log C_{e q}$ (Figure 1), the parameters $n$ and $k$ were obtained from the slope intercept, respectively.

Figure 2 shows the plot of $1 /(x / m)$ versus $1 / C$ eq for phenol using Coal $\left(\mathrm{C}\left(\mathrm{H}_{3} \mathrm{PO}_{4}\right), \mathrm{C}\left(\mathrm{ZnCL}_{2}\right), \mathrm{C}(\mathrm{NaOH})\right)$ as adsorbent, and Langmuir constants were determined from the slope and intercept.

$$
\text { From the Equation } \frac{1}{x / m}=\frac{1}{q_{m}}+\frac{1}{q_{m} k_{l}} \cdot \frac{1}{C_{e q}} \text { we }
$$
had

$$
\frac{x}{m}=k_{F} \cdot\left(C_{e q}\right)^{1 / n}
$$

The fixing of the phenol on Coal activated by $\mathrm{NaOH}$

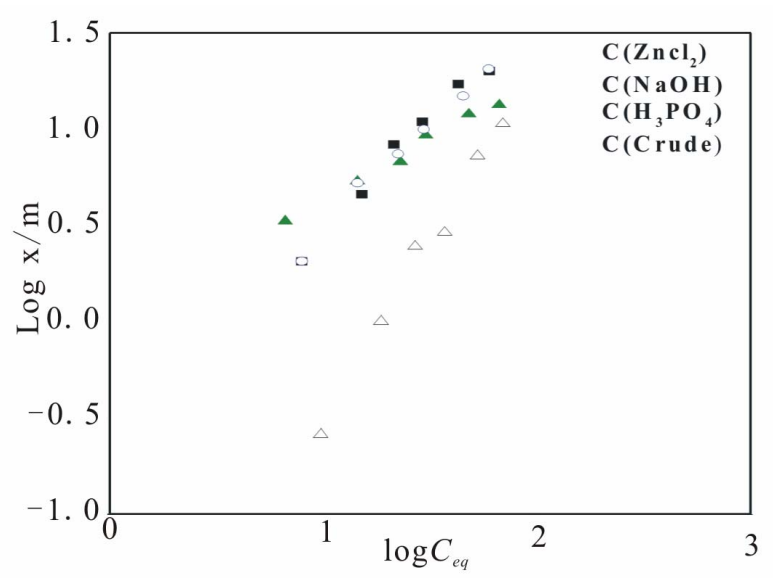

Figure1. Freundlich adsorption isotherm for phenol (Coals activated by $\mathrm{NaOH}, \mathrm{ZnCl}_{2}, \mathrm{H}_{3} \mathrm{PO}_{4}$ ).

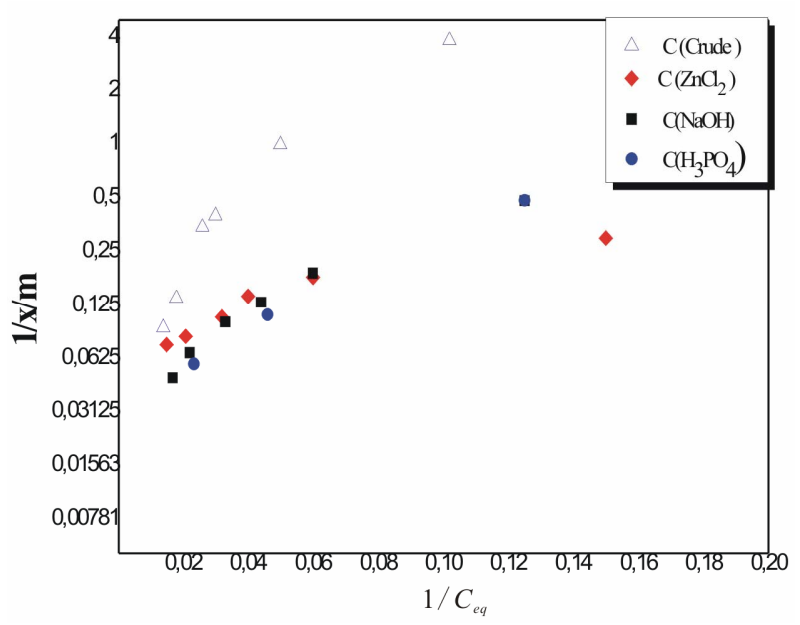

Figure2. Langmuir adsorption isotherm for phenol (Coal activated by $\mathrm{NaOH}, \mathrm{ZnCl}_{2}, \mathrm{H}_{3} \mathrm{PO}_{4}$ and raw coal). 
complies with the Freundlich model with a regression coefficient of $\mathrm{R}^{2}=0.98$.

The constant characteristic $\mathrm{K}_{\mathrm{F}}=1.01 ; \mathrm{n}=1.59$ and the isotherm follow the Equation $\mathrm{x} / \mathrm{m}=1.01\left(C_{e q}\right)^{0.62}$

The phenol fixing isotherm on Coal activated by $\mathrm{ZnCl}_{2}$ obeys the Freundlich model with a regression coefficient of $\mathrm{R}^{2}=0.98$

The constant $\mathrm{K}_{\mathrm{F}}=0.23 ; \mathrm{n}=0.91$

$=>\mathrm{x} / \mathrm{m}=0.23\left(C_{e q}\right)^{1.09}$

The fixing of the phenol on coal activated by $\mathrm{H}_{3} \mathrm{PO}_{4}$, obeys the Freundlich model with a regression coefficient of $\mathrm{R}^{2}=0.98$

The constant $\mathrm{K}_{\mathrm{F}}=0.20 ; \mathrm{n}=0.85$

$=>\mathrm{x} / \mathrm{m}=0.20\left(C_{e q}\right)^{1.16}$

The phenol fixing on raw Coal obeys the Freundlich model with the regression coefficient $\mathrm{R}^{2}=0.98$

The constant $\mathrm{K}_{\mathrm{F}}=0.0033 ; \mathrm{n}=0.53$

$=>\mathrm{x} / \mathrm{m}=0.0033\left(C_{e q}\right)^{1.8}$

The value of the constant $1 / \mathrm{n}$ indicates the adsorption intensity

$\mathrm{n}<1$ : weak adsorbent

$\mathrm{n}>1$ : good adsorbent

n C NaOH good adsorbent

n C ZnCl ${ }_{2}$ good adsorbent

n C $\mathrm{H}_{3} \mathrm{PO}_{4}$ good adsorbent

n C Crude weak adsorbent

Capacities of phenol adsorption on these coal samples can be classified as follows:

n C $\mathrm{NaOH}>\mathrm{n} \mathrm{C} \mathrm{ZnCl}_{2}>\mathrm{n} \mathrm{C} \mathrm{H}_{3} \mathrm{PO}_{4}>$ n C Crude

Therefore, one can conclude that residual coal treated with $\mathrm{NaOH}$ gives the best results among the adsorbents studied.

Figure 3 is a typical plot obtained from investigation in phenol adsorption during equilibrium time of three different carbon types. It is evident that the rapid initial rate of adsorption decreases markedly within time and gave a gradual approach to an equilibrium condition, which was attained after 5 min of contact between phenol solution and activated carbon. It is noticed that after 05-min contact between phenol solution and activated coal with $\left(\mathrm{NaOH} ; \mathrm{H}_{3} \mathrm{PO}_{4} ; \mathrm{ZnCl}_{2}\right)$, we obtained $62.4 \%$; $43.08 \%$; $24.87 \%$ of phenol retention respectively.

Figure 3 also shows a comparison of the adsorption capacity of the three types of carbon. The Coal activated with $\mathrm{NaOH}$ had obviously a larger adsorption capacity than the other two activated carbons.

\section{Conclusions}

The study of adsorption onto Coal activated carbon in a liquid-solid fluidized bed for phenol, gave rise to the following conclusions:

1. The order of adsorption capacities of adsorbents

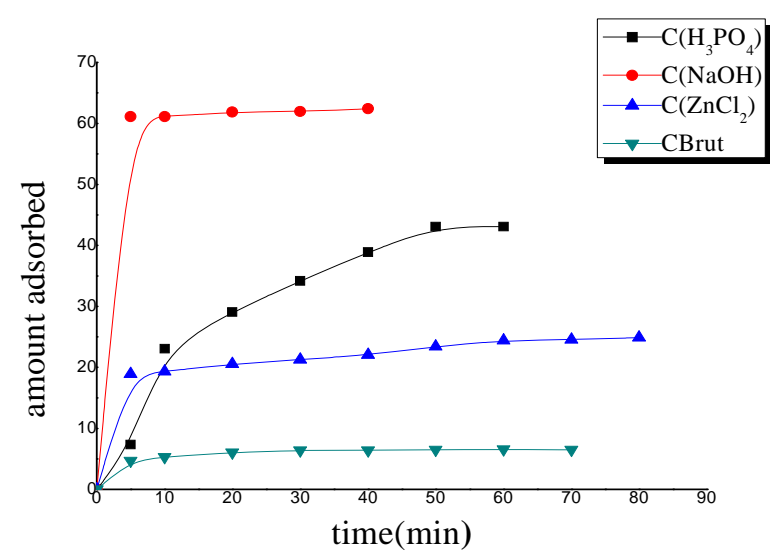

Figure3. Effect of contact time on the removal of phenol (Coal activated by $\mathrm{H}_{3} \mathrm{PO}_{4}, \mathrm{ZnCL}_{2}$, and $\mathrm{NaOH}$.

studied for phenol was in the following array $\mathrm{NaOH}>$ $\mathrm{H}_{3} \mathrm{PO}_{4}>\mathrm{Zncl}_{2}$

2. The adsorption capacity of Coals increased after treatment with sodium hydroxide, phosphoric acid and zinc chloride.

3. Coal treated with sodium hydroxide was found to give better results among the adsorbents studied.

4. The adsorption isotherm obtained from Coals treated can be represented by a Langmuir and Freundlich Equations for phenol solute.

\section{References}

[1] E. G. Furuya, H. T. Chang and K. E. Miura, "Purif," Technology, Vol. 11, No. 2, 1997, p. 69.

[2] W. J. Weber and J. C. Morris, "Kinetics of Adsorption in Columns of Fluidized Media,” Journal Water Pollution Control Federation, Vol. 37, No. 4, 1965, p. 425.

[3] G. Kovacik and B. Wong, "Preparation of Activated Carbon from Western Canadian High Rank Coals," Fuel Process Technology, Vol. 41, No. 2, 1995, pp. 89-99.

[4] T. Wigmans and C. P. Bean, "Industrial Aspects of Production and Use of Activated Carbons," Carbon, Vol. 27, No. 1, 1989, pp. 13-22.

[5] H. Teng and H. C. Lin, “Activated Carbon Production from Low Ash Subbituminous Coal with $\mathrm{CO}_{2}$ Activation,” AIChE Journal, Vol. 44, No. 5, 1998, pp. 1170-1177.

[6] F. M. Caturla, S, F. Molina, R. Rodriguez, "Preparation of Activated Carbon by Chemical Activation with $\mathrm{Zncl}_{2}$," Carbon, Vol. 29, No. 7, 1991, pp. 999-1007.

[7] M. Jagtoyen, M. J. Thwaites, B. Stencel and F. D. McEnaney, “Adsorbent Carbon Synthesis from Coals by Phosphoric Acid Activation,” Carbon, Vol. 30, No. 7, 1992, pp. 1089-1096.

[8] M. J. Illán-Gómez, C. Garclá-Garclá and C. Salinas-Martınéz, “Activated carbons,” Energy Fuels, Vol. 10, No. 5, 1996, pp. 1108-1114.

[9] E. Costa, G. Calleja and L. Marijuan, “Adsorpt,” Science 
\& Technology, Vol. 122, No.1, 1987, p. 59.

[10] M. S. Abdo, S. Nosier and Y. A. Tawil, "Environ,” Science A, Vol. 32, No. 4, 1997, p. 1159.

[11] F. R. Rodriguez, M. S. Molina and M. T. Gonzàlez, "The Use of Steam and $\mathrm{CO}_{2}$ as Activating Agents in the Preparation of Activated Carbons," Carbon, Vol. 33, No. 1,
1995, pp. 15-23.

[12] R. Juang, F. Wu and R. Tseng, “Adsorption Isotherms of Phenolic Compounds from Aqueous Solutions onto Activated Carbon Fibers," Journal of Chemical Engineering, Vol. 41, No. 3, 1996, p. 487. 